OPEN ACCESS

Edited by:

Heikki Helanterä,

University of Oulu, Finland

Reviewed by:

Adam R. Smith,

George Washington University,

United States

Brian R. Johnson,

University of California, Davis,

United States

*Correspondence:

Judith Korb

judith.korb@biologie.uni-freiburg.de

Specialty section:

This article was submitted to

Social Evolution

a section of the journal

Frontiers in Ecology and Evolution

Received: 29 June 2021

Accepted: 08 October 2021

Published: 26 October 2021

Citation:

Bernadou A, Kramer BH and Korb J (2021) Major Evolutionary

Transitions in Social Insects, the Importance of Worker Sterility

and Life History Trade-Offs.

Front. Ecol. Evol. 9:732907.

doi: 10.3389/fevo.2021.732907

\section{Major Evolutionary Transitions in Social Insects, the Importance of Worker Sterility and Life History Trade-Offs}

\author{
Abel Bernadou' ${ }^{1}$, Boris H. Kramer ${ }^{2}$ and Judith Korb ${ }^{3 *}$ \\ ${ }^{1}$ Department of Zoology and Evolutionary Biology, University of Regensburg, Regensburg, Germany, ${ }^{2}$ Faculty of Science \\ and Engineering, Theoretical Research in Evolutionary Life Sciences, RUG, Groningen, Netherlands, ${ }^{3}$ Department of \\ Evolutionary Biology and Ecology, Institute of Biology I (Zoology), University of Freiburg, Freiburg im Breisgau, Germany
}

The evolution of eusociality in social insects, such as termites, ants, and some bees and wasps, has been regarded as a major evolutionary transition (MET). Yet, there is some debate whether all species qualify. Here, we argue that worker sterility is a decisive criterion to determine whether species have passed a MET (= superorganisms), or not. When workers are sterile, reproductive interests align among group members as individual fitness is transferred to the colony level. Division of labour among cooperating units is a major driver that favours the evolution of METs across all biological scales. Many METs are characterised by a differentiation into reproductive versus maintenance functions. In social insects, the queen specialises on reproduction while workers take over maintenance functions such as food provisioning. Such division of labour allows specialisation and it reshapes life history trade-offs among cooperating units. For instance, individuals within colonies of social insects can overcome the omnipresent fecundity/longevity trade-off, which limits reproductive success in organisms, when increased fecundity shortens lifespan. Social insect queens (particularly in superorganismal species) can reach adult lifespans of several decades and are among the most fecund terrestrial animals. The resulting enormous reproductive output may contribute to explain why some genera of social insects became so successful. Indeed, superorganismal ant lineages have more species than those that have not passed a MET. We conclude that the release from life history constraints at the individual level is a important, yet understudied, factor across METs to explain their evolutionary success.

Keywords: ants, bees, life history trade-off, major evolutionary transitions, social evolution, superorganism, social insects, termites

\section{INTRODUCTION}

Life on earth has evolved through rare but large steps called major evolutionary transitions (METs; Maynard Smith and Szathmáry, 1995; Michod, 1997; Bourke, 2011; West et al., 2015). During such a transition, organisation is shifted. Individual units (e.g., cells or insects) which were previously independent, integrate into a new larger "entity" (e.g., multicellular organisms or 
superorganisms) (see Table 1 for glossary of bold terms) (Maynard Smith and Szathmáry, 1995; Bourke, 2011; West et al., 2015; Figure 1). A MET has therefore been defined to be accomplished, when the fitness of the lower-level units is completely transferred to the higher level (see e.g., Okasha, 2005, 2006). As a consequence, the higher-level unit becomes the common unit of selection, evolutionary fitness interests among lower-level units are aligned and within-lower-level conflict becomes rare. The transition from multicellular organisms to eusocial animal societies, such as honey bee colonies, has been referred to as a MET (e.g., Maynard Smith and Szathmáry, 1995; Bourke, 2011, 2019; Szathmáry, 2015; West et al., 2015; Helanterä, 2016; Boomsma and Gawne, 2018). Yet debates exist whether they qualify as such. The large degree of social organisation that exists in social insects is a major reason for these discussions. Even the term eusociality covers considerable variation (e.g., Bourke, 1999, 2019; Anderson and McShea, 2001; Korb and Heinze, 2016; Boomsma and Gawne, 2018 and references therein). The variation in social organisation has been categorised into three steps that characterise a MET (e.g., Bourke, 2011; Korb and Heinze, 2016 for details). Using these three steps, we outline when we consider eusocial species as superorganismal (i.e., having passed a MET). We apply the theoretically founded criterion of complete fitness transfer to the higher level (Okasha, 2006). Thus, in our opinion, a MET is only realised in species with sterile workers (including soldiers; i.e., true neuters) because only then the lower-level fitness of colony members (lower-level units; i.e., workers/soldiers and queens as well as kings in termites) is completely transferred to the colony level (higher-level unit). This colony level fitness is realized by a colonies' queen/king, which represent the exclusive germline of these superorganisms. Workers can only increase their fitness by increasing the reproductive success of the colony, which means by supporting their germline, the queen/king, to which they are related. Under these conditions, the inclusive fitness of workers/soldiers consist exclusively of the indirect fitness component, which is the (direct) fitness of the higher evolutionary unit (i.e., the colony). Therefore, conflict over reproduction among group members is absent as reproductive interests are aligned. Based on this consideration, we highlight the importance of division of labour and specialisation among lower-level units in overcoming life history trade-offs as potential drivers toward METs.

\section{THREE STEPS CHARACTERISE A MAJOR EVOLUTIONARY TRANSITION}

Three steps characterise a MET (e.g., Bourke, 2011; Korb and Heinze, 2016 for details). These steps go along with important changes in terms of cooperation and conflict within groups (see Queller and Strassmann, 2009; Figure 1A):

(1) Group formation (cooperation: intermediate, conflict: low). The first stage, group formation, results from individuals coming together. It is selected mainly because individuals gain direct fitness, for instance, from selfish herd
TABLE 1 | Definition of terms used in the paper.

\begin{tabular}{|c|c|}
\hline Term & Definition \\
\hline Eusociality & $\begin{array}{l}\text { Insects/animals that are characterised by overlapping } \\
\text { generations, reproductive division of labour, and brood care. }\end{array}$ \\
\hline Superorganisms & $\begin{array}{l}\text { Eusocial insects/animals with sterile workers/soldiers, and } \\
\text { accordingly a complete germline (queen/king) - soma } \\
\text { (workers, soldiers) separation; in superorganisms the fitness of } \\
\text { the individuals (lower-level units) is transferred to the colony } \\
\text { (higher-level unit) realized via the colonies' germline, the queen } \\
\text { (and sometimes also a king). Superorganims qualify as having } \\
\text { passed a major evolutionary transition. }\end{array}$ \\
\hline
\end{tabular}

Sterile workers Workers which have completely lost their reproductive organs. Alternatively, workers can be considered as sterile if their ovaries are no longer involved in reproduction but only in alternative functions.

Direct fitness Number of own offspring (or better, allele copies) produced and transmitted to the next generation without the help of others; equivalent to classical Darwinian fitness.

Indirect fitness Number of offspring (or better, allele copies) that relatives produce and transmit to the next generation due to the help of the altruist, weighed by relatedness.

By-product A cost-free interaction between individuals/units from which all mutualism participants derive direct fitness benefits as by-products of the action of others.

Cooperation A costly interaction between individuals/units from which all participants derive net direct fitness benefits.

Altruism

A costly interaction between individuals/units in which one partner, the altruist, increases the direct fitness of another individual, recipient, with net direct fitness costs for the altruist.

Evolutionary Individuals/units, which invest less than their fair share into an cheaters association, thus exploiting their partners; selection generally favours such cheaters in the short-run, so that they often can "threaten" the stability of a cooperative interaction.

Fraternal Major evolutionary transitions that originated from associations transitions of similar, related units; "more of the same" which results in division of labour after the association formed.

Egalitarian Major evolutionary transitions that originated from associations transitions of different, disparate units, both partners reproduce; each unit contributed different functions right from the beginning to the association.

They are highlighted in bold, when first mentioned in the text.

effects, improved protection against predators, facilitated resource exploitation, and/or energetic benefits as in the case of birds migrating in flocks. Taxon-specific ecology is important and different ecological conditions favour associations in different species and in different populations (e.g., Korb and Heinze, 2008; Jetz and Rubenstein, 2011; Rubenstein and Abbot, 2017 and reference therein). Strictly speaking, group formation is often a result of by-product mutualisms (sensu Bshary and Bergmüller, 2008) as no costs are involved for the participating individuals. Group formation is facilitated by a lack of local scale competition over resources or mating partners. Division of labour (DOL) plays a minor role and these associations are often transient. None of the eusocial animals belongs into this category as they live in non-transient groups.

(2) Group maintenance (cooperation: increasing from intermediate to high, conflict: decreasing from intermediate 
A

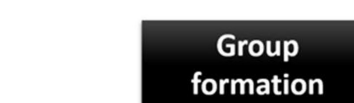

Group

站增

Solitary individuals

Colonies with totipotent individuals
Group

maintenance
Group

transformation
B

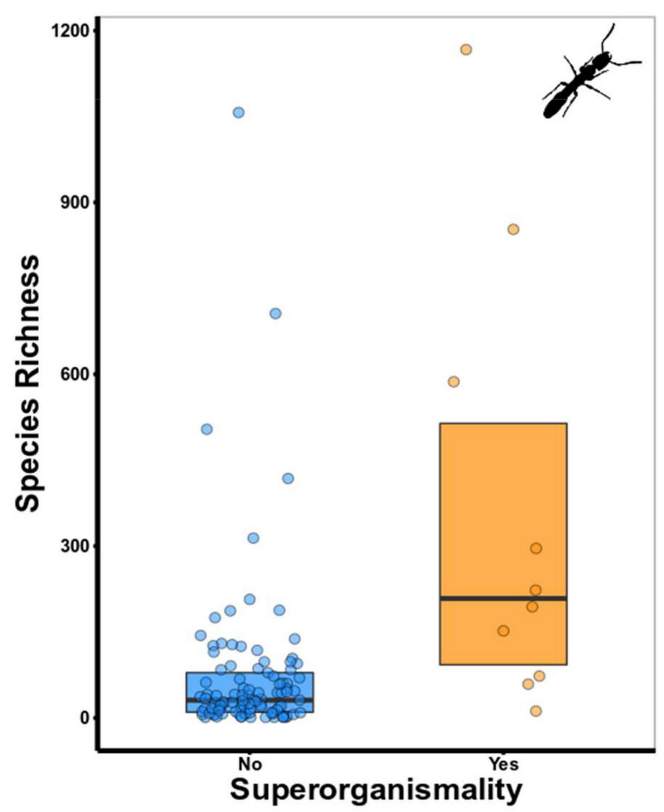

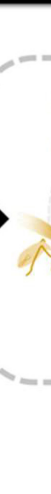
Evolution of individuality

C

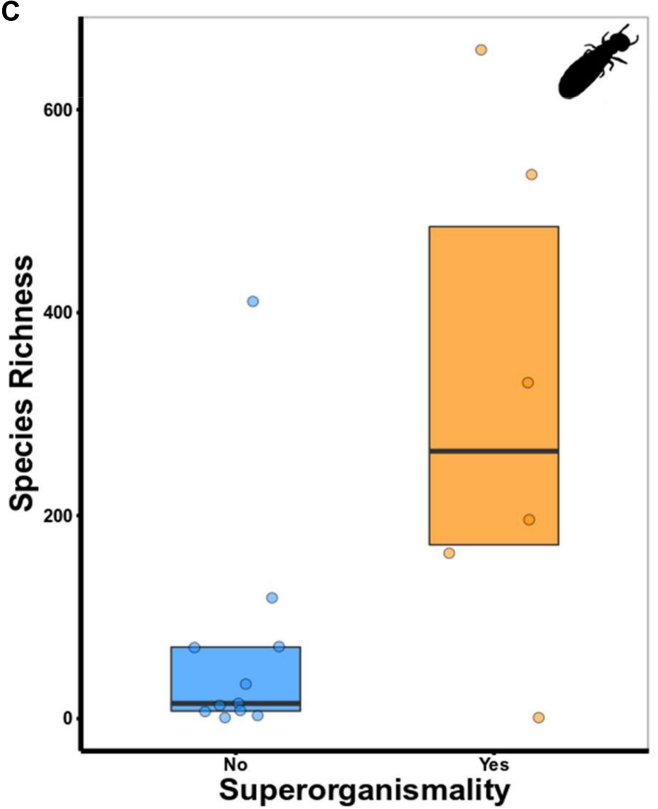

FIGURE 1 | (A) The three key steps that characterise a major evolutionary transition (following Bourke, 2011, 2019). These steps go along with important changes in terms of cooperation and conflict within groups (see main text for details). (B) Species richness in superorganismal and non-superorganismal ant genera. Species richness was significantly higher in superorganismal than non-superorganismal ant genera (Mann-Whitney $U$ test: $N=337, W=355, P<0.005$ ). Controlling for phylogenetic dependencies, a phylogenetic ANOVA was run on a subset of 111 genera for which a phylogeny was available. They showed that genera with sterile workers $(N=10)$ had higher species richness than genera that we do not consider superorganismal $(F=24.56, P \leq 0.005)$ (see Supplementary Material for more details). (C) Species richness in superorganismal and non-superorganismal termite lineages. There was a trend for species richness to be significantly higher in superorganismal than non-superorganismal termite lineages (Mann-Whitney $U$ test: $N=17, W=13.5, P=0.056$ ). The phylogenetic ANOVA revealed no differences in species richness between superorganismal $(N=6)$ and non-superorganismal $(N=6)$ termite lineages $(N=12, F=2.28, P=0.371)$.

to low). The second step, group maintenance, refers to established groups, which are not transient. Non-transient groups often arise through parent/offspring associations with extended brood care (i.e., subsociality) (Grosberg and Strathmann, 2007; Michod, 2007; Boomsma, 2009; Griesser et al., 2017). DOL appears as another major driver of the evolution of permanent groups (e.g., Michod, 2007). DOL results in complementary functions and/or traits, which increase the direct fitness of interacting partners. Continued selection of specialisation can lead to reciprocal dependence and further enhanced fitness (for detail, see below). Such permanent groups are generally characterised by cooperation rather than by-product mutualisms. Hence costs are involved and the evolutionary stability of groups can be threatened by evolutionary cheaters. Thus, the evolution of mechanisms of conflict resolution, such as partner choice or sanctioning of selfish individuals, is important for the evolutionary stability of these groups (e.g., Frank, 1998).

In the case of social insects (or more broadly, all fraternal associations), indirect fitness benefits derived from helping 
relatives are of major importance (e.g., Korb and Heinze, 2004; Foster et al., 2006; Boomsma, 2009; Abbot et al., 2011). They facilitate stable maintenance of associations, and potential selection against cheating, for instance through the evolution of self-restraint (e.g., Frank, 1998; Ratnieks et al., 2006 and references therein). In the case of the evolution of altruism, relatedness is even a necessary pre-requisite (Foster et al., 2006; Boomsma, 2009; Abbot et al., 2011). Importantly in all associations of step 2, single individuals still have the potential to produce own offspring (i.e., gain direct fitness benefits) so that fitness is not completely transferred from the lower to the higher level and conflict over reproduction among lower-level units remains.

Many systems of cooperatively breeding birds and mammals (Rubenstein and Abbot, 2017) can be classified as having crossed the group maintenance step. Among the eusocial animals, all those species, in which workers and/or soldiers (i.e., the altruistic castes) can still reproduce, belong into this category. This includes, e.g., social mole rats, many social aphids and thrips, all termite species except the Termitidae, and all social Hymenopterans in which workers can produce males (including the honey bee) (Korb and Heinze, 2016; see Supplementary Table 1).

(3) Group transformation (cooperation: high; conflict: low). The third stage, group transformation, generally considers groups that have passed a MET (Okasha, 2006; Bourke, 2011; West et al., 2015; Boomsma and Gawne, 2018). Formally, it corresponds to the emergence of new higherlevel entities (here, groups composed of individuals) (Okasha, 2006; Bourke, 2011; West et al., 2015). Most researchers would agree that social insects in the third stage are superorganisms. Yet, disagreement and debates remain about the strict criterion or thresholds at which a new higher level entity emerges. To date, mostly definitions are favoured which centre around the loss of totipotency of individuals (e.g., Boomsma and Gawne, 2018) or which are based on a continuum of the extent of cooperation and conflict (Queller and Strassmann, 2009) (for a discussion, see below). In the current paper, we strictly apply the theoretically founded ultimate criterion of complete transfer of fitness of lower-units to the higherlevel unit (see above).

Accordingly, in our opinion, in social insects, group transformation is reached when workers are sterile, so that they cannot gain any direct fitness. We consider worker sterility to be reached when workers have completely lost their reproductive organs or when ovaries are no longer involved in reproduction but "only" necessary for other physiological or developmental processes (Khila and Abouheif, 2010). Under such conditions, workers cannot gain any direct fitness, but only indirect fitness via the reproductive success of the colony. The colony is the unit of selection and the indirect fitness of its members becomes the direct fitness of the colony. Social insects with sterile workers qualify as "true" superorganisms with a complete separation of the germline (queen, and in termites also a king) and the soma (workers and sometimes soldiers) (Korb and Heinze, 2016).

From this perspective, surprisingly few eusocial insect species have passed the MET - and no eusocial mammal - all of which qualify in analogy of multicellular organisms as true superorganisms. Examples are the Termitidae among the termites, and several genera of social Hymenoptera, such as Pheidole, Monomorium, and Cardiocondyla (see Supplementary Table 1, for simplicity we only included here species with workers that have completely lost their ovaries).

\section{WHICH FACTORS FACILITATE THE 'PROGRESSION' TOWARD A MAJOR EVOLUTIONARY TRANSITION?}

As shown above, step 2, stable group maintenance, is critical to understand the transition toward a MET. Which factors lead to stable group maintenance and may facilitate a MET? For fraternal transitions, a major factor for a successful transition seems to be the relatedness among cooperating individuals (e.g., Hamilton, 1964; Korb and Heinze, 2004; Foster et al., 2006; Boomsma, 2009; Abbot et al., 2011). This close evolutionary linkage among cooperating partners can be rephrased as common ancestry (relatedness) and aligned future (obligate uniparental vertical transmission) for fraternal and egalitarian transitions, respectively (Korb, 2010). In addition, all METs are characterised by DOL, and benefits derived from DOL appear to be major drivers for stable group maintenance.

Division of labour emerges spontaneously, when two or more individuals are grouped together (e.g., Fewell and Page, 1999). Hence, DOL plays a pivotal role during the initial steps of group formation (Michod, 2007). When associated with net direct fitness benefits for interacting partners, group maintenance can be selected, along with specialisation of partners for different tasks. The latter results in increased efficiency and fitness (Oster and Wilson, 1978; Michod, 2007; West et al., 2015; West and Cooper, 2016; Cooper and West, 2018) as well as mutual dependency between interacting partners, which are no longer all-rounders (loss of individual totipotency) (McShea, 2002 but also Michod, 2006, 2007; Bourke, 2011; West et al., 2015; Birch, 2017; Cooper and West, 2018). Together with conflict resolution mechanisms, mutual dependency is of fundamental importance for the stability of groups. Benefits associated with increased group sizes can re-enforce these processes, resulting in positive feedback loops with increasing task division and specialisation (Michener, 1964; Karsai and Wenzel, 1998; Michod, 2007; Korb, 2010; Bourke, 2011) and the occurrence of novel emergent properties (for social insects: more efficient communication via trail pheromones, construction of mounds) (Korb, 2010; Leonhardt et al., 2016).

Strikingly, all fraternal transitions (note, the multiple independent origins of multicellularity and of superorganismality in social insects) are centred on reproductive DOL. Some parts of the emerging group (multicellular organisms, superorganisms) specialise in reproduction, which are sometimes but not always (e.g., plants, hydra) separated as a germline, while the remaining 
units perform all the others tasks, such as intake of food, nutrient provisioning, mobility, and/or defence. By outsourcing reproduction versus maintenance to different individuals within a group, reproductive DOL freed individuals (i.e., lower-level units) partially from the corresponding life history constraint. As the "degrees of freedom" increase, life history trade-offs of individuals can be overcome and eventually be reshaped. We, therefore, propose that DOL-associated vanquishing of life history trade-off to be another driver that can lead from group maintenance to group transition, and thus to METs.

\section{THE "VANQUISHING" OF LIFE HISTORY TRADE-OFFS, A SPECIAL "BENEFIT" OF DIVISION OF LABOUR}

There are a number of causes for the occurrence of life history trade-offs, some of the most common, non-mutually exclusive ones are: (i) pleiotropic genes, (ii) endocrine mechanisms (e.g., JH, testosterone), (iii) developmental constraints, and/or (iv) limiting resources (i.e., allocation trade-offs) (e.g., Stearns, 1992). Several of these constraints can be overcome either through differential regulation of gene expression between tissues/castes (fraternal transitions) or through "independent evolution" (different gene sets) (egalitarian transitions).

Prominent examples are social insects, which have apparently overcome the omnipresent trade-off between fecundity and longevity (Monroy Kuhn and Korb, 2016 and references therein), that commonly constrains the fitness of solitary organisms. In eusocial insects, the queens (and in termites also kings) are the only individuals reproducing within a colony. At the same time, they can reach lifespans of decades with reproduction increasing longevity, while the non-reproducing workers often live for a few months only (Keller and Genoud, 1997; Keller, 1998; Schrempf et al., 2005; Kramer and Schaible, 2013; Korb and Thorne, 2017). In ants (Kramer and Schaible, 2013) and termites (Korb and Thorne, 2017) longevity of queens increases with social complexity. In termites, the most longlived females occur in superorganismal species that passed a MET: queens of the fungus-growing Macrotermes termites can live for more than 20 years and produce 20,000 eggs per day (Korb and Thorne, 2017). Thus, they are arguably the most fecund terrestrial animals. A mechanistic example of how trade-offs can be overcome are cases of caste-specific gene expression that are associated with gene duplications. Multi-copy genes can be co-opted during evolution for castespecific functions, thus e.g., vanquishing trade-offs associated with pleiotropic gene functions (Gadagkar, 1997; Korb, 2016). A recent study suggests that this has been the case in termites (Shigenobu et al., 2021). We hypothesise that mechanisms vanquishing life history trade-off, are less studied drivers toward METs, which are most prominent in superorganismal species (Blacher et al., 2017). They might contribute to explain the ecological and evolutionary success of social insects (social Hymenoptera $^{1}$; termites: Kambhampati and Eggleton, 2000;

${ }^{1}$ www.antcat.org
Korb and Thorne, 2017 and references therein). To test the hypothesis that social insects, which have passed a MET are more successful than those that have not, we used species richness as a potential proxy of evolutionary success (for more information, see Supplementary Table 1, Data Sheet 1). Ant genera with sterile workers have, indeed, an increased species richness compared to those which were non-superorganismal (i.e., no sterile workers, Figure 1B - for simplicity of identification, we only used species, in which workers have completely lost their ovaries). For termites, direct comparison between lineages with sterile workers and those without showed a trend for increased species richness in lineages without worker reproduction but this trend disappeared when data were controlled for phylogeny (Figure 1C).

\section{DISCUSSION}

Our definition of a MET in social insects (sterility of workers, including soldiers, i.e., true neuters) differs from existing definitions (e.g., Helanterä, 2016; Boomsma and Gawne, 2018; Bourke, 2019) and it apparently seems to align with former ones (e.g., Wheeler, 1911; Wells et al., 1929; Buss, 1987; Hölldobler and Wilson, 2009). However, the latter studies, which used worker sterility as a defining hallmark for superorganisms, were not formulated within a MET framework and the authors had different reasons for delimiting superorganisms unlinked to a formal foundation in evolutionary theory. By contrast, we based our criterion on the ultimate explanation that the fitness of these lower-level units is only completely transferred to the higher colony level when there are true neuters. Therefore, our definition offers two major advantages: it is founded in (i) fundamental first principles of evolution that (ii) apply across all METs. We think these two points are major advantages of our definition.

As, recommended by Herron (2021), our definition is not guided by impressive complex traits of specific taxa, such as the dance language in the honey bee, mound building in some termites or complex societies observed in army ants or fungus-growing ants and termites. Some of these species would qualify as formal evolutionary superorganisms, others not. Many other organisms evolved complex traits (e.g., bacterial biofilm). Yet, these organisms would not be considered to have passed a MET. Our criterion is also not guided by specific social insects. Many of the currently available definitions have implicitly social Hymenoptera in mind. For example, "loss of totipotency" as a superorganism/MET criterion does not mean loss of direct fitness in termites. Among the so called "lower termites" there a many species, in which workers lost totipotency as they cannot become winged sexuals but they still commonly reproduce within the natal nest and gain considerable direct fitness (Korb and Hartfelder, 2008; Roisin and Korb, 2011). These species also have morphologically differentiated workers, another criterion sometimes used to define superorganism. Yet, none of these species would be defined as superorganisms in a MET context. Similar arguments would apply to social thrips or aphids (e.g., morphological soldier castes; e.g., Chapman et al., 2008; 
Pike and Foster, 2008), which most researcher would not consider as superorganismal.

Our definition could be criticised as Gardner and Grafen (2009) have shown in their model that sterile workers are neither necessary nor sufficient for superorganisms to evolve. Yet, they defined superorganisms "as a group that wields adaptations in its own right" (more like Wheeler, 1911; Wells et al., 1929; Buss, 1987; Hölldobler and Wilson, 2009). This is not the MET concept, we apply here.

An important point in the discussion of distinguishing superorganisms is conflict within colonies. According to our definition there is no conflict over reproduction within monogamous colonies though conflict of the sex ratio may still exist in social Hymenoptera. We argue, this is similar to multicellular organisms, in which conflict over the sex ratio can still occur due to maternal inheritance of, e.g., mitochondria (Burt and Trivers, 2006). One situation under which conflict over reproduction can occur even in species with sterile neuters are polygamous colonies. Polygamy is generally considered to be a derived trait in social insects (e.g., Boomsma, 2009). After a MET, new conflicts can be evolve, similar as after the evolution of individuality in multicellular organisms.

One solution to overcome the conflict argument is the superorganismality approach by Queller and Strassmann (2009) and Strassmann and Queller (2010) to regard associations as a continuum along the two axes of cooperation and conflict (Sherman et al., 1995). While we are much in favour of this concept, it does not allow to delimit METs, which seem to exist in nature. During a transition process - as might be happening in social insects as a whole - it might be difficult to identify specific criteria, which become apparent only later. While our definition can be criticised (e.g., because it excludes some species with very complex sociality), we hope it contributes to clarify what is a MET and how best to define it. We think that METs should be defined using criteria that are based on common ultimate/evolutionary principles that apply across transitions.

\section{REFERENCES}

Abbot, J., Abe, J., Alcock, J., Alizon, S., Alpedrinha, J. A. C., Andersson, M., et al. (2011). Inclusive fitness theory and eusociality. Nature 471, E1-E4. doi: 10.1038 /nature09831

Anderson, C., and McShea, D. W. (2001). Individual versus social complexity, with particular reference to ant colonies. Biol. Rev. 76, 211-237. doi: 10.1017/ s1464793101005656

Birch, J. (2017). The Philosophy of Social Evolution. Oxford: Oxford University Press.

Blacher, P., Huggins, T. J., and Bourke, A. F. G. (2017). Evolution of ageing, costs of reproduction and the fecundity-longevity trade-off in eusocial insects. Proc. R. Soc. B. 284:20170380. doi: 10.1098/rspb.2017.0380

Boomsma, J. J. (2009). Lifetime monogamy and the evolution of eusociality. Philos. Trans. R. Soc. B 364, 3191-3207. doi: 10.1098/rstb.2009.0101

Boomsma, J. J., and Gawne, R. (2018). Superorganismality and caste differentiation as points of no return: how the major evolutionary transitions were lost in translation. Biol. Rev. 93, 28-54. doi: 10.1111/brv.12330

Bourke, A. F. G. (1999). Colony size, social complexity and reproductive conflict in social insects. J. Evol. Biol. 12, 245-257. doi: 10.1046/j.1420-9101.1999.00028.x

Bourke, A. F. G. (2011). Principles of Social Evolution. Oxford: Oxford University Press.

Bourke, A. F. G. (2019). Inclusive fitness and the major transitions in evolution. Curr. Opin. Insect Sci. 34, 61-67. doi: 10.1016/j.cois.2019.03.008

\section{DATA AVAILABILITY STATEMENT}

The original contributions presented in the study are included in the article/Supplementary Material, further inquiries can be directed to the corresponding author.

\section{AUTHOR CONTRIBUTIONS}

JK conceived the idea to this manuscript. JK and AB wrote the manuscript. BK edited the manuscript and analysed the data. $\mathrm{AB}, \mathrm{BK}$, and $\mathrm{JK}$ collected the data. All authors have read and approved the manuscript.

\section{FUNDING}

This research was funded within the framework of the DFG Research Unit “So-long” (FOR2281): BE6684/1-1, 261675780, and KO1895/20-2.

\section{ACKNOWLEDGMENTS}

We wish to thank the members of the Research Unit "So-long" for discussions and Heikki Helanterä and two reviewers for helpful comments on the manuscript. We would also like to thank Andrew Burchell for providing us with the phylogeny for the ant genera.

\section{SUPPLEMENTARY MATERIAL}

The Supplementary Material for this article can be found online at: https://www.frontiersin.org/articles/10.3389/fevo.2021. 732907/full\#supplementary-material

Bshary, R., and Bergmüller, R. (2008). Distinguishing four fundamental approaches to the evolution of helping. J. Evol. Biol. 21, 405-420.

Burt, A., and Trivers, R. L. (2006). Genes in Conflict. Boston, MA: Belknap Press of Harvard University Press.

Buss, L. W. (1987). The Evolution of Individuality. Princeton, NJ: Princeton University Press.

Chapman, T. W., Crespi, B. J., and Perry, S. P. (2008). "The evolutionary ecology of eusociality in Australian gall thrips: a 'model clades' approach," in Ecology of Social Evolution, eds J. Korb and J. Heinze (Berlin: Springer), 57-83.

Cooper, G. A., and West, S. A. (2018). Division of labour and the evolution of extreme specialization. Nat. Ecol. Evol. 2, 1161-1167. doi: 10.1038/s41559-0180564-9

Fewell, J. H., and Page, R. E. Jr. (1999). The emergence of division of labour in forced associations of normally solitary ant queens. Evol. Ecol. Res. 1, 537-548.

Foster, K. R., Wenseleers, T., and Ratnieks, F. L. W. (2006). Kin selection is the key to altruism. Trends Ecol. Evol. 21, 57-60. doi: 10.1016/j.tree.2005.11.020

Frank, S. A. (1998). Foundations of Social Evolution. Princeton, NJ: Princeton University Press.

Gadagkar, R. (1997). The evolution of caste polymorphism in social insects: genetic release followed by diversifying evolution. J. Genet. 76, 167-179. doi: 10.1007/ BF02932215

Gardner, A., and Grafen, A. (2009). Capturing the superorganism: a formal theory of group adaptation. J. Evol. Biol. 22, 659-671. doi: 10.1111/j.1420-9101.2008. 01681.x 
Griesser, M., Drobniak, S. M., Nakagawa, S., and Botero, C. A. (2017). Family living sets the stage for cooperative breeding and ecological resilience in birds. PLoS Biol. 15:e2000483. doi: 10.1371/journal.pbio.2000483

Grosberg, R. K., and Strathmann, R. R. (2007). The evolution of multicellularity: a minor major transition? Ann. Rev. Ecol. Evol. Syst. 38, 621-654. doi: 10.1146/ annurev.ecolsys.36.102403.114735

Hamilton, W. D. (1964). The genetical evolution of social behaviour I. J. Theor. Biol. 7, 1-16. doi: 10.1016/0022-5193(64)90038-4

Helanterä, H. (2016). An organismal perspective on the evolution of insect societies. Front. Ecol. Evol. 4:6. doi: 10.3389/fevo.2016.00006

Herron, M. D. (2021). What are the major transitions? Biol. Philos. 36:2. doi: 10.1007/s10539-020-09773-z

Hölldobler, B., and Wilson, E. O. (2009). The Superorganisms: The Beauty, Elegance, and Strangeness of Insect Societies. New York, NY: W. W Norton \& Company.

Jetz, W., and Rubenstein, D. R. (2011). Environmental uncertainty and the global biogeography of cooperative breeding in birds. Curr. Biol. 21, 72-78. doi: 10. 1016/j.cub.2010.11.075

Kambhampati, S., and Eggleton, P. (2000). "Taxonomy and phylogeny of termites," in Termites: Evolution, Sociality, Symbiosis and Ecology, eds T. Abe, D. E. Bignell, and M. Higashi (Dordrecht: Kluwer Academic Publishers), $1-23$.

Karsai, I., and Wenzel, J. W. (1998). Productivity, individual-level and colonylevel flexibility, and organization of work as consequences of colony size. Proc. Natl. Acad. Sci. U. S. A. 96, 8665-8669. doi: 10.1073/pnas.95.15. 8665

Keller, L. (1998). Queen lifespan and colony characteristics in ants and termites. Insectes Soc. 45, 235-246. doi: 10.1007/s000400050084

Keller, L., and Genoud, M. (1997). Extraordinary lifespans in ants: a test of evolutionary theories of ageing. Nature 389, 958-960. doi: 10.1038/40130

Khila, A., and Abouheif, E. (2010). Evaluating the role of reproductive constraints in ant social evolution. Philos. Trans. R. Soc. Lond. B Biol. Sci. 365, 617-630. doi: $10.1098 /$ rstb.2009.0257

Korb, J. (2010). "Social insects, major evolutionary transitions and multilevel selection," in Animal Behaviour: Evolution and Mechanisms, ed. P. Kappeler (Heidelberg: Springer Press), 179-211.

Korb, J. (2016). Genes underlying reproductive division of labor in termites with comparisons to social Hymenoptera. Front. Ecol. Evol. 4:e45. doi: 10.3389/fevo. 2016.00045

Korb, J., and Hartfelder, K. (2008). Life history and development - a framework for understanding developmental plasticity in lower termites. Biol. Rev. 83, 295-313. doi: 10.1111/j.1469-185X.2008.00044.x

Korb, J., and Heinze, J. (2004). Multilevel selection and social evolution of insect societies. Naturwissenschaften 91, 291-304. doi: 10.1007/s00114-004-0529-5

Korb, J., and Heinze, J. (2008). Ecology of Social Evolution. Heidelberg: Springer Press.

Korb, J., and Heinze, J. (2016). Major hurdles for the evolution of sociality. Annu. Rev. Entomol. 61, 297-316. doi: 10.1146/annurev-ento-010715-023711

Korb, J., and Thorne, B. (2017). "Sociality in termites," in Comparative Social Evolution, eds D. R. Rubenstein and P. Abbot (Cambridge: Cambridge University Press), 124-152.

Kramer, B. H., and Schaible, R. (2013). Colony size explains the life span differences between queens and workers in eusocial Hymenoptera. Biol. J. Linn. Soc. 109, 710-724. doi: 10.1111/bij.12072

Leonhardt, S. D., Menzel, F., Nehring, V., and Schmitt, T. (2016). Ecology and evolution of communication in social insects. Cell 164, 1277-1287. doi: 10.1016/ j.cell.2016.01.035

Maynard Smith, J., and Szathmáry, E. (1995). The Major Transitions in Evolution. Oxford: Freeman.

McShea, D. W. (2002). A complexity drain on cells in the evolution of multicellularity. Evolution 56, 441-452. doi: 10.1111/j.00143820.2002.tb01357.x

Michener, C. D. (1964). Reproductive efficiency in relation to colony size in hymenopterous societies. Insectes Soc. 11, 317-342. doi: 10.1007/BF02227433

Michod, R. E. (1997). Evolution of the individual. Am. Nat. 150, S5-S21. doi: $10.1086 / 286047$

Michod, R. E. (2006). The group covariance effect and fitness trade-offs during evolutionary transitions in individuality. Proc. Natl. Acad. Sci. U. S. A. 103, 9113-9117. doi: 10.1073/pnas.0601080103
Michod, R. E. (2007). Evolution of individuality during the transition from unicellular to multicellular life. Proc. Natl. Acad. Sci. U. S. A. 104, 8613-8618. doi: 10.1073/pnas.0701489104

Monroy Kuhn, J. M., and Korb, J. (2016). Social insects: aging and the re-shaping of the fecundity/longevity trade-off with sociality. Curr. Opin. Insect Sci. 16, vii-x. doi: $10.1016 /$ j.cois.2016.06.002

Okasha, S. (2005). Multilevel selection and the major transitions in evolution. Philos. Sci. 72, 1013-1025. doi: 10.1086/508102

Okasha, S. (2006). Evolution and the Levels of Selection. Oxford: Oxford University Press.

Oster, G. F., and Wilson, E. O. (1978). Caste and Ecology in the Social Insects. Princeton, NJ: Princeton University Press.

Pike, N., and Foster, W. A. (2008). "The ecology of altruism in a clonal insect," in Ecology of Social Evolution, eds J. Korb and J. Heinze (Berlin: Springer), 37-56.

Queller, D. C., and Strassmann, J. E. (2009). Beyond society: the evolution of organismality. Philos. Trans. R. Soc. B 364, 3143-3155. doi: 10.1098/rstb.2009. 0095

Ratnieks, F. L. W., Foster, K. R., and Wenseleers, T. (2006). Conflict resolution in insect societies. Annu. Rev. Entomol. 51, 581-608. doi: 10.1146/annurev.ento. 51.110104 .151003

Roisin, Y., and Korb, J. (2011). "Social organisation and the status of workers in termites," in Biology of Termites: A Modern Synthesis, eds D. E. Bignell, Y. Roisin, and N. Lo (Heidelberg: Springer), 133-164.

Rubenstein, D. R., and Abbot, P. (2017). Comparative Social Evolution. Cambridge: Cambridge University Press.

Schrempf, A., Heinze, J., and Cremer, S. (2005). Sexual cooperation: mating increases longevity in ant queens. Curr. Biol. 15, 267-270. doi: 10.1016/j.cub. 2005.01.036

Sherman, P. W., Lacey, E. A., Reeve, H. K., and Keller, L. (1995). The eusociality continuum. Behav. Ecol. 6, 102-108.

Shigenobu, S., Hayashi, Y., Watanabe, D., Tokuda, G., Hojo, M. Y., Toga, K., et al. (2021). Genomic and transcriptomic analyses of the subterranean termite Reticulitermes speratus: gene duplication facilitates social evolution. bioRxiv [Preprint]. doi: 10.1101/2021.07.11.451559

Stearns, S. C. (1992). The Evolution of Life Histories. Oxford: Oxford University Press.

Strassmann, J. E., and Queller, D. C. (2010). The social organism: congresses, parties, and committees. Evolution 64, 605-616. doi: 10.1111/j.1558-5646.2009. 00929.x

Szathmáry, E. (2015). Toward major evolutionary transitions theory 2.0. Proc. Natl. Acad. Sci. U. S. A. 112, 10104-10111. doi: 10.1073/pnas.1421398112

Wells, H. G., Huxley, J. S., and Wells, G. P. (1929). The Science of Life. London, UK: The Waverley Publishing Company Ltd.

West, S. A., and Cooper, G. A. (2016). Division of labour in microorganisms: an evolutionary perspective. Nat. Rev. Microbiol. 14, 716-723. doi: 10.1038/ nrmicro.2016.111

West, S. A., Fisher, R. M., Gardner, A., and Kiers, E. T. (2015). Major evolutionary transitions in individuality. Proc. Natl. Acad. Sci. U. S. A. 112, 10112-10119. doi: $10.1073 /$ pnas.1421402112

Wheeler, W. M. (1911). The ant-colony as an organism. J. Morphol. 22, 307-325. doi: 10.1002/jmor.1050220206

Conflict of Interest: The authors declare that the research was conducted in the absence of any commercial or financial relationships that could be construed as a potential conflict of interest.

Publisher's Note: All claims expressed in this article are solely those of the authors and do not necessarily represent those of their affiliated organizations, or those of the publisher, the editors and the reviewers. Any product that may be evaluated in this article, or claim that may be made by its manufacturer, is not guaranteed or endorsed by the publisher.

Copyright (c) 2021 Bernadou, Kramer and Korb. This is an open-access article distributed under the terms of the Creative Commons Attribution License (CC BY). The use, distribution or reproduction in other forums is permitted, provided the original author(s) and the copyright owner(s) are credited and that the original publication in this journal is cited, in accordance with accepted academic practice. No use, distribution or reproduction is permitted which does not comply with these terms. 